\title{
ON THE SUPER-STABILITY OF TRIGONOMETRIC HILBERT-VALUED FUNCTIONAL EQUATIONS
}

\author{
H. REZAEI
}

Abstract. We generalize the super-stability result for cosine functional equation mappings with values in the field of complex numbers to the case of an arbitrary Hilbert space with the Hadamard product. On the other hand, by an example we prove that this generalization is not true for sine functional equation.

Mathematics subject classification (2010): Primary: 39B72, 39B82; secondary: 46E40.

Keywords and phrases: Trigonometric functions, stability, super-stability, Hilbert-valued function.

\section{REFERENCES}

[1] T. AOKI, On the stability of the linear transformation in Banach spaces, J.Math. Soc. Japan 2 (1950), 64-66.

[2] R. BAdora And R. Ger, On some trigonometric functional inequalities, Functional Equations Results and Advances (2002), 3-15.

[3] J. A. BAKer, The stability of the cosine equation, Proc. Amer. Math. Soc. 80 (1980), 411-416.

[4] J. A. BAKer, J. LAWrence, AND F. ZorzitTo, The stability of the equation $f(x+y)=f(x) f(y)$, Proc. Amer. Math. Soc. 74 (1979), 242-246.

[5] D. G. Bourgin, Approximate isometries, Bull. Amer. Math. Soc. 52 (1946), 704-714.

[6] P. Gavruta, On the stability of some functional equations, in: Stability of Mappings of Hyers-Ulam Type, Hadronic Press, 1994, pp. 93-98.

[7] P. Gavruta, An answer to a question of Th. M. Rassias and J. Tabor on mixed stability of mappings, Bul. Stiinţ. Univ. Politeh. Timiş. Ser. Mat. Fiz. 42 (1997), 1-6.

[8] P.W. Cholewa, The stability of the sine equation, Proc. Amer. Math. Soc. 88 (1983), 631-634.

[9] S. CZERwik, Functional Equations and Inequalities in Several Variables, World Scientific, Hackensacks, New Jersey, 2002.

[10] Pl. Kannappan, The functional equation $f(x y)+f\left(x y^{-1}\right)=2 f(x) f(y)$ for groups, Proc. Am. Math. Soc. 19 (1968), 69-74.

[11] D. H. HYERS, On the stability of the linear functional equation, Proceedings of the National Academy of Sciences of the United States of America, 27 (1941), 222-224.

[12] D. H. Hyers And Th. M. Rassias, Approximate homomorphisms, Aequat. Math. 44 (1992), 125153.

[13] D. H. Hyers, G. Is AC AND Th. M. RASSIAS, Stability of Functional Equations in Several Variables, Birkhauser, Boston, Basel, Berlin, 1998.

[14] S. M. Jung, Hyers-Ulam-Rassias Stability of Functional Equations in Nonlinear Analysis, Springer, New York, 2011.

[15] G. H. KIm, A Stability of the generalized sine functional equations, J. Math. Anal. Appl. 331 (2007), $886-894$.

[16] M. KUCZMA, An introduction to the theory of functional equations and inequalities, PWN, Warszawa, Krak ow, and Katowice, 1985.

[17] TH. M. RASSiAS, Problem 18, In "Report on the 31st ISFE", Aequationes Math. 47 (1994), 312-313.

[18] TH. M. Rassias, On the stability of the linear mapping in Banach spaces, Proc. Amer. Math. Soc. 72, 2 (1978), 297-300. 
[19] Th. M. Rassias And J. TABor, What is left of Hyers-Ulam stability?, J. Nat. Geom. 1 (1992), $65-69$.

[20] H. ReZAei And M. Sharifzadeh, On the Super-Stability of Exponential Hilbert-Valued Functional Equations, J. Inequal. Appl. (2011), 8 pages. (doi:10.1186/1029-242X-2011-114)

[21] S. M. Ulam, A Collection of Mathematical Problems, Interscience Tracts in Pure and Applied Mathematics no. 8, Interscience, New York, NY, USA, 1960. 